\title{
Experimental Evaluation of the Ability of an Auxiliary Heating Device to Reduce the Condensation Risk around Built-in Wardrobes of Apartment Buildings in Winter
}

\author{
Chae Lyn Lee ${ }^{1, *}$, Hyun Hwa Lee $^{2}$, Jae Han Lim ${ }^{1, *}$, and Seung Yeong Song ${ }^{1}$ \\ ${ }^{1}$ Department of Architectural Engineering, Ewha Womans University, Seoul, Korea \\ ${ }^{2}$ Korea Institute of Civil Engineering and Building Technology, Gyeonggi-do, Korea
}

\begin{abstract}
Recently, there has been an increase in the condensation and mould problems of apartment buildings in Korea owing to the high insulation and high air-tightness performance of buildings, which increase energy savings. Condensation is generally found in winter on furniture back panels and adjacent surfaces of the wall, floor, and ceiling. These problems are related to the weather conditions and indoor room conditions in winter. To solve these problems, an auxiliary heating device that can be installed was developed. The purpose of this study was to evaluate condensation risk in the condensation vulnerable areas around built-in furniture of apartment buildings by installing an auxiliary heating device. The experimental results reveal that condensation risk can be reduced by comparing the thermal environment around the builtin furniture with and without installation of an auxiliary heating device in winter. Furthermore, they reveal that it is possible to increase the surface temperature of vulnerable areas around built-in wardrobe by applying an auxiliary heating device to minimize condensation problems by using a minimum device.
\end{abstract}

\section{Introduction}

As the energy-saving design code for buildings has recently been strengthened in South Korea, the heat insulation and airtightness performances of apartment buildings have gradually improved. However, various indoor household activities like drying clothes, cooking and showering generate a large quantity of moisture inside a dwelling. This increases the likelihood of condensation in thermally vulnerable areas [1]. A dispute between occupants and a constructor over condensation defects tends to increase in the early days of moving into a new apartment building. To improve the condensation problem in new apartment buildings, the Korean government has developed and enacted the Design Standard for Preventing Condensation in Apartment Buildings with notification of the Ministry of Land, Infrastructure and Transport in accordance with the Regulations on Housing Construction Standards. Nevertheless, according to a report compiled by the Apartment Defect Dispute Mediation Committee, which is affiliated with the Ministry of Land, Infrastructure and Transport, the cumulative number of mediation cases about apartment defects, which were registered between 2010 and 2015, was 8,859 (14\% of total cases), and more and more cases are waiting to be mediated every year [2]. The wall accounts for as much as about $33 \%$ of the total defect cases. The space for built-in wardrobes in apartment buildings is often subject to condensation. In particular, the back panel and adjacent wall, floor, and ceiling seem to be vulnerable to condensation.
Condensed liquid water on floors or wall finishes damages other finishing materials, furniture, things stored in the wardrobe, and property. Once a built-in wardrobe is installed, it is difficult to remove or completely dismantle, and the space between the wardrobe and the wall is not accessible. For this reason, the control of condensation and related damage is a difficult task as long as occupants lead their everyday life. Moreover, if condensation occurs, insulation, interior finishes, and furniture materials need to be repaired or replaced, which is costly $[3,4]$.

In accordance with the Regulation on Housing Construction Standards, when a new apartment building is completed, the constructor should provide drawings of the condensation vulnerable areas for each built-in wardrobe to help prevent condensation. It is also required that a heater, a ventilator, or an exhaust system be installed in the space for a built-in wardrobe [5]. Every apartment building in South Korea adopts a radiant floor heating system. Condensation on the walls of apartment buildings can be prevented by burying floor-heating pipes near the exterior wall. Unfortunately, the majority of the existing apartment buildings have not laid floor-heating pipes beneath built-in wardrobes. Accordingly, the surface temperature of the space for a built-in wardrobe, which is close to the exterior wall, is lowered and thus the likelihood of condensation significantly increases. However, no appropriate countermeasure has been established to prevent condensation of built-in wardrobes in existing apartment buildings. This study proposes an auxiliary heating

Corresponding author: limit0@ewha.ac.kr 
device, which is easy to install in the vent of a built-in wardrobe, and verifies its anti-condensation performance by conducting an experiment in a real apartment.

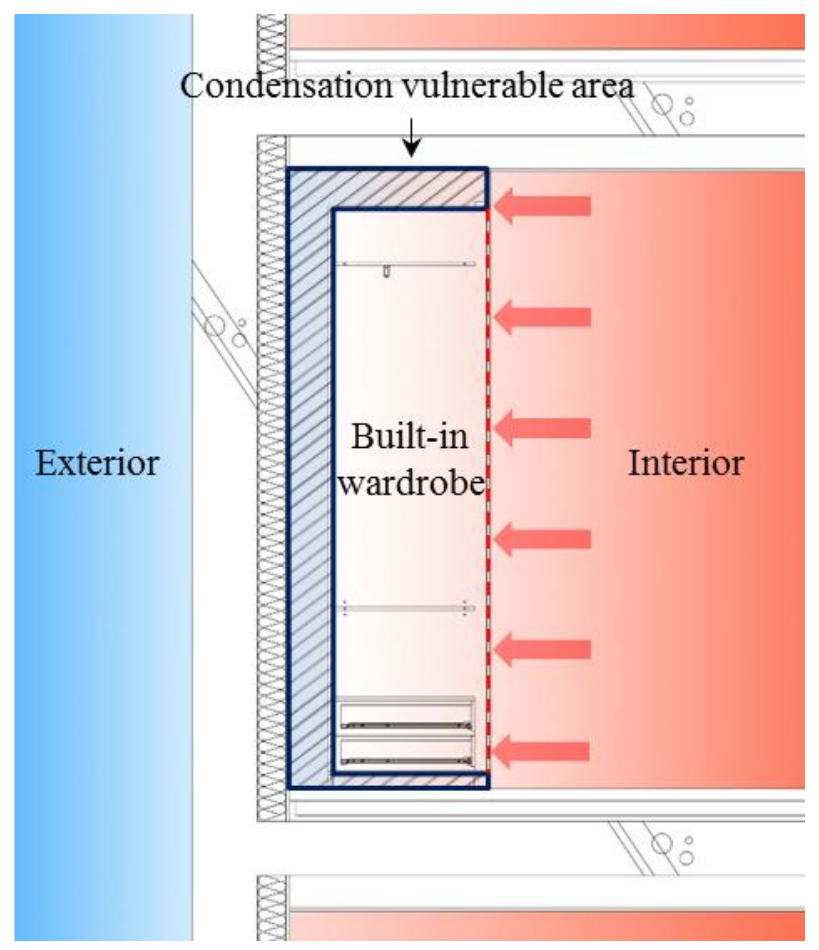

Fig. 1. Diagram of the occurrence of condensation in a built-in wardrobe.

\section{Current design status of built-in wardrobes in apartment buildings}

In a condensation vulnerable area of a built-in wardrobe, condensation occurs owing to either a local decrease in surface temperature, which is attributable to heat transfer loss through wall-slab structures, or to an increase in the indoor dew point temperature due to a sudden increase in moisture related to occupants' indoor activities.

As shown in Figure 1, the built-in wardrobe is typically installed around $100 \mathrm{~mm}$ away from the wall. A vent is also installed inside the built-in wardrobe to prevent condensation by ventilating the wardrobe space. However, as clothes and bedding densely fill the interior space, the built-in wardrobe becomes thermally insulated and difficult to ventilate. In particular, since no floorheating pipe is installed beneath the built-in wardrobe in the existing apartment buildings, and a thermal bridge occurs in the corner of the apartment building envelope, for which internal insulation is designed, a local decrease in surface temperature occurs. Thus, the air temperature at the back of the built-in wardrobe is lowered, which significantly increases the likelihood of condensation. Even if the heat insulation and thermal bridge are improved in the design stage to prevent condensation in a built-in wardrobe, a large amount of moisture can be created depending on occupants' household activities. In this case, as the absolute humidity rises inside and at the back of the built-in wardrobe, the occurrence of condensation on the back panel of wardrobe becomes probable. Consequently, the space of a built-in wardrobe is very vulnerable to condensation caused by various factors, including a local decrease in surface temperature, which is attributable to a thermal bridge in the corner of apartment building envelope, and difficult ventilation of an interior space [6].

To solve the condensation problem of vulnerable areas in built-in wardrobes of the existing apartment buildings, this study proposes an auxiliary heating device that can increase the ambient temperature of a built-in wardrobe and keep it above the dew point temperature. Temperatures were actually measured in consideration of the indoor environment during winter.

\section{Experimental set-up}

\subsection{Test room in apartment buildings}

To prevent condensation, an auxiliary heating device was installed in a built-in wardrobe of an apartment building. The change in the thermal environment was monitored by operating the device. This field experiment was conducted in unit houses of an apartment building in Goyang-si, Gyeonggi-do, which had been completed in 2007. The same type of built-in wardrobe was installed in the target unit houses, which were located either in the middle or on the edge of the building. The experiment focused on the impact of outdoor thermal environment and the anti-condensation effect of the auxiliary heating device.

The area of exclusive use for each unit house was $54 \mathrm{~m} 2$, and all the houses had the same floor plan. Figure 2 shows the locations of built-in wardrobes. Glass wool with a thickness of $95 \mathrm{~mm}$ (thermal conductivity: $0.035 \mathrm{~W} / \mathrm{mK}$ ) was applied to the outer wall of the side house, which makes contact with the outdoor air. Glass wool with a thickness of $70 \mathrm{~mm}$ was used for the outer wall of the balcony. However, no heat insulation was applied to the wall of the vertical shaft inside the houses.

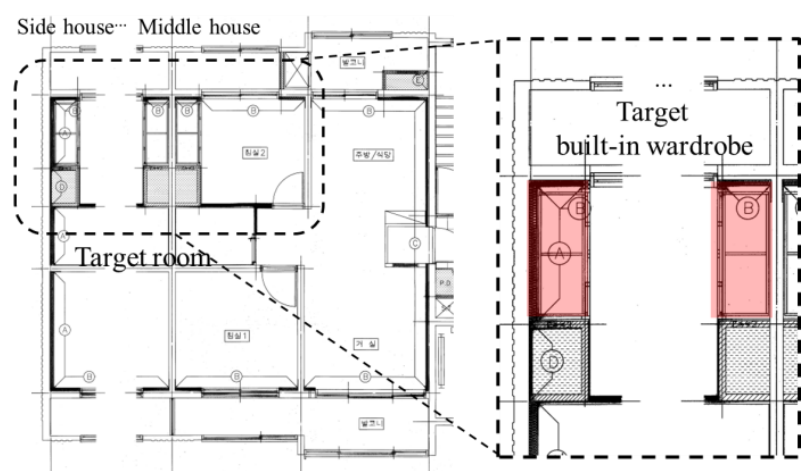

Fig. 2. Plan of unit house and target built-in wardrobe for the experiment.

\subsection{Indoor thermal environment conditions}

Indoor thermal environment condition was operated using the floor heating system in the target apartment considering the preliminary study $[8,9,10]$ and the 
indoor heating environment condition of domestic condensation prevention performance standard. For this reason, as for indoor temperature, the floor heating temperature was set to $20{ }^{\circ} \mathrm{C}-22^{\circ} \mathrm{C}$. As for the indoor relative humidity, a humidifier was used to reproduce the living environment. The indoor humidity condition was maintained by operating an electric fan during the experiment.

\subsection{Built-in wardrobe conditions}

The target built-in wardrobe was adjacent to the vertical shaft and the balcony that makes contact with outdoor air. It had dimensions of $1.5 \mathrm{~m}(\mathrm{D}) \times 2.2 \mathrm{~m}(\mathrm{H}) \times 0.6 \mathrm{~m}(\mathrm{~W})$. The back panel of the built-in wardrobe was $13 \mathrm{~mm}$ away from the wall. As illustrated in Figure 3, the built-in wardrobe consisted of two units, each of which had a circular vent with a diameter of $90 \mathrm{~mm}$ in its upper part.

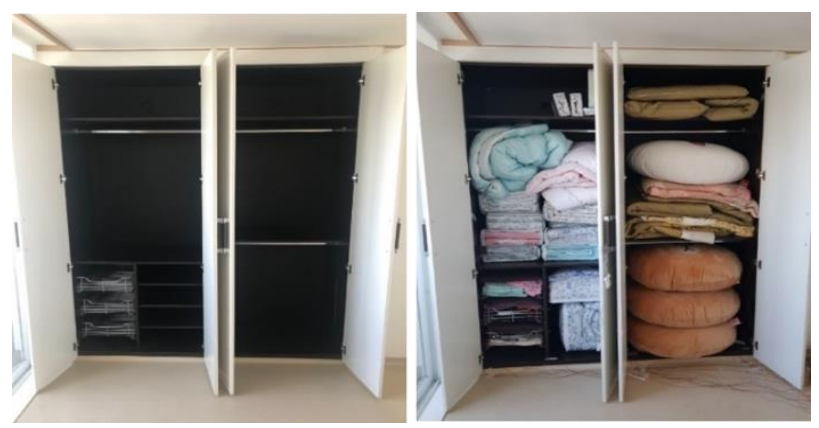

Fig. 3. Front view of the target built-in wardrobe.

\subsection{Auxiliary heating device}

The auxiliary heating device used in this study increased the air temperature and surface temperatures of the back panel and the rear wall by blowing warm air into the space between the back panel and the rear wall. This heating device consisted of a heating element, a control unit, and a power supply unit. As a combination of a heater, fan, and grill, the device operated the heater and blew warm air through the fan and the grill. Dead air was forced to flow by the warm air from the fan. Figure 4 show the auxiliary heating device and its installation.

In consideration of the shape and size of the existing vent of the built-in wardrobe, a circular heating device with a diameter of $90 \mathrm{~mm}$ was adopted. As the vent was located in the upper part of the target built-in wardrobe, the auxiliary heating device also placed in the upper part (see the yellow shaded part in Figure 5). The capacity of the auxiliary heating device was $15 \mathrm{~W}$. Table 1 presents the experimental alternatives with or without the auxiliary heating device.

\subsection{Measurement items and locations}

To measure the surface temperature of the rear wall facing the back panel of the built-in wardrobe, nine points (P1-P9) were selected, and thermocouples were attached to them. In addition, another nine points (P10 -
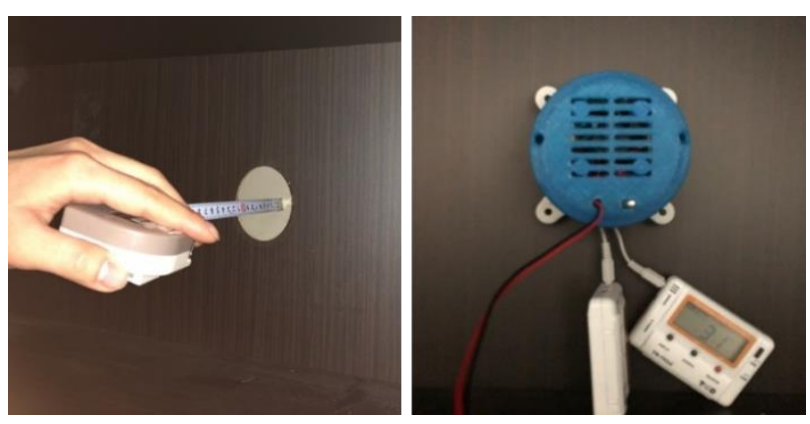

Fig. 4. Vent and auxiliary heating device in the target built-in wardrobe.

P18) were also selected on the back panel to identify the surface temperature of the back panel of the built-in wardrobe. Thus, surface temperature was measured at 18 points. To see the variations in temperature and humidity around the built-in wardrobe, temperature and humidity data loggers were attached inside the room, inside the built-in wardrobe, and in the upper and lower parts of the air cavity between the back panel and the rear wall. A temperature and humidity data logger was also installed outside the room to measure and record the outdoor thermal environment during the experiment. All the data were measured and recorded every $10 \mathrm{~min}$. Figure 5 illustrates measurement items and locations in the builtin wardrobe. Table 2 presents the specifications of the measuring instruments.

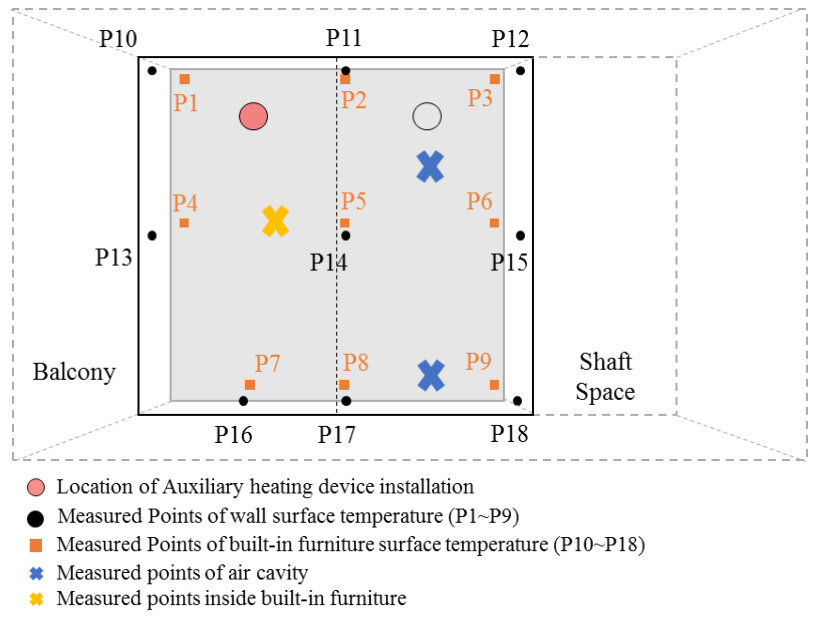

Fig. 5. Measurement items and locations.

Table 1. Measuring instruments and specifications.

\begin{tabular}{|c|c|}
\hline Classification & Specifications \\
\hline $\begin{array}{c}\text { Temperature and } \\
\text { humidity } \\
\text { recorder }\end{array}$ & $\begin{array}{c}\text { Model }: \text { TR-74Ui } \\
\text { Accuracy }: \pm 0.5^{\circ} \mathrm{C}\end{array}$ \\
\hline Data Logger & $\begin{array}{c}\text { Model }: \text { GL } 820 \\
\text { Clock accuracy }: \pm 0.002 \% \\
\text { Accuracy }: \pm 0.1 \% \text { at }-200 \text { to } 400^{\circ} \mathrm{C}\end{array}$ \\
\hline Thermocouple & $\begin{array}{r}\text { T-type }: \text { TS-T25-TE } \\
\text { Measurement range }:-200 \text { to } 350^{\circ} \mathrm{C} \\
\text { Accuracy }: \pm 0.5^{\circ} \mathrm{C} \text { or } 0.4 \%\end{array}$ \\
\hline
\end{tabular}


Table 3. Temperature and humidity outside and inside the room and inside the built-in wardrobe.

\begin{tabular}{|c|c|c|c|c|c|c|c|c|c|c|c|}
\hline & & \multicolumn{2}{|c|}{ Case 1} & \multicolumn{2}{|c|}{ Case 2} & \multicolumn{2}{|c|}{ Case 3} & \multicolumn{2}{|c|}{ Case 4} & \multicolumn{2}{|c|}{ Case 5} \\
\hline & & $\mathrm{T}\left({ }^{\circ} \mathrm{C}\right)$ & $\mathrm{RH}(\%)$ & $\mathrm{T}\left({ }^{\circ} \mathrm{C}\right)$ & RH (\%) & $\mathrm{T}\left({ }^{\circ} \mathrm{C}\right)$ & RH (\%) & $\mathrm{T}\left({ }^{\circ} \mathrm{C}\right)$ & RH (\%) & $\mathrm{T}\left({ }^{\circ} \mathrm{C}\right)$ & RH (\%) \\
\hline \multirow{3}{*}{ Outside } & Min. & -11.8 & 26.5 & -3.7 & 14.8 & -3.7 & 14.8 & -11.8 & 26.5 & -3.7 & 14.8 \\
\hline & Max. & 5.0 & 73.9 & 6.4 & 90.4 & 6.4 & 90.4 & 5.0 & 73.9 & 6.4 & 90.4 \\
\hline & Ave. & -6.5 & 43.0 & 1.5 & 51.6 & 1.5 & 51.6 & -6.5 & 43.0 & 1.5 & 51.6 \\
\hline \multirow{3}{*}{ Room } & Min. & 16.3 & 12.0 & 16.9 & 55.0 & 20.6 & 15.0 & 17.3 & 11.0 & 24.1 & 49.0 \\
\hline & Max. & 2.1 & 87.0 & 25.1 & 85.0 & 24.9 & 69.0 & 23.7 & 90.0 & 27.1 & 59.0 \\
\hline & Ave. & 20.3 & 53.5 & 21.9 & 64.5 & 22.9 & 56.5 & 19.6 & 50.1 & 25.9 & 55.7 \\
\hline \multirow{3}{*}{$\begin{array}{l}\text { Inside } \\
\text { built-in } \\
\text { wardrobe }\end{array}$} & Min. & 17.6 & 18.0 & 18.9 & 54.0 & 16.8 & 31.0 & 15.9 & 15.0 & 22.9 & 54.0 \\
\hline & Max. & 21.0 & 76.0 & 24.0 & 79.0 & 21.0 & 71.0 & 21.1 & 81.0 & 24.4 & 65.0 \\
\hline & Ave. & 19.2 & 53.2 & 21.7 & 64.3 & 19.8 & 64.9 & 18.2 & 46.3 & 23.7 & 64.0 \\
\hline
\end{tabular}

Table 2. Experimental alternatives with or without the auxiliary heating device.

\begin{tabular}{|c|c|c|c|}
\hline & $\begin{array}{c}\text { Location of test } \\
\text { apartment unit }\end{array}$ & $\begin{array}{c}\text { Auxiliary } \\
\text { heating device } \\
\text { operation }\end{array}$ & $\begin{array}{c}\text { Outdoor } \\
\text { Temperature }\end{array}$ \\
\hline Case 1 & Middle house & $\mathrm{x}$ & $\mathrm{L}$ \\
\hline Case 2 & Middle house & $\mathrm{o}$ & $\mathrm{H}$ \\
\hline Case 3 & Side house & $\mathrm{x}$ & $\mathrm{H}$ \\
\hline Case 4 & Side house & $\mathrm{o}$ & $\mathrm{L}$ \\
\hline Case 5 & Side house & $\mathrm{o}$ & $\mathrm{H}$ \\
\hline
\end{tabular}

$\mathrm{L}:-11.8^{\circ} \mathrm{C}-5.0^{\circ} \mathrm{C}$

$\mathrm{H}:-3.7^{\circ} \mathrm{C}-6.4^{\circ} \mathrm{C}$

\section{Experimental results}

\subsection{Air temperature changes}

Table 3 provides temperature and humidity ranges measured inside and outside the room and in the built-in wardrobe during the experiment. The temperatures inside the room, inside the built-in wardrobe, and in the upper and lower parts of air cavity at the rear of the wardrobe were identified according to the operation of the auxiliary heating device in each unit house. Figure 6 shows the differences between the indoor temperature and the temperatures inside the built-in wardrobe and in the upper part or the bottom part of the air cavity at the rear of the wardrobe, in each alternative.

In Case 1 and Case 3, where the auxiliary heating device was not installed, the differences between the indoor temperature and the temperatures inside the built-in wardrobe and in the upper part or the bottom part of the air cavity at the rear of the wardrobe were conspicuous and showed similar trends. However, Case 1 showed that the temperature inside the built-in wardrobe continued to be higher than that in Case 3 .

In Case 2, the maximum difference between the indoor temperature and the temperature inside the built-in wardrobe was $1.9^{\circ} \mathrm{C}$. This means that both places kept similar temperatures. Besides, intermittently, the temperatures inside the built-in wardrobe and in the upper and bottom parts of air cavity at the rear of the wardrobe were higher than the indoor temperature. This seemed to be because of the influence of the auxiliary heating device. However, the temperature in the bottom part of air cavity was lower than that of the indoor temperature by as much as $5.5^{\circ} \mathrm{C}$.

On the other hand, in Case 4 and Case 5, compared with the indoor temperature, the temperature inside the builtin wardrobe was lower by as much as $3.1{ }^{\circ} \mathrm{C}-3.6{ }^{\circ} \mathrm{C}$, and the temperatures in the upper and bottom parts of the air cavity at the rear of the wardrobe were lower by as much as $5.3{ }^{\circ} \mathrm{C}-5.6{ }^{\circ} \mathrm{C}$ and $7.5{ }^{\circ} \mathrm{C}-8.7{ }^{\circ} \mathrm{C}$, respectively. Accordingly, the side houses showed a clear temperature difference irrespective of the operation of the auxiliary heating device.
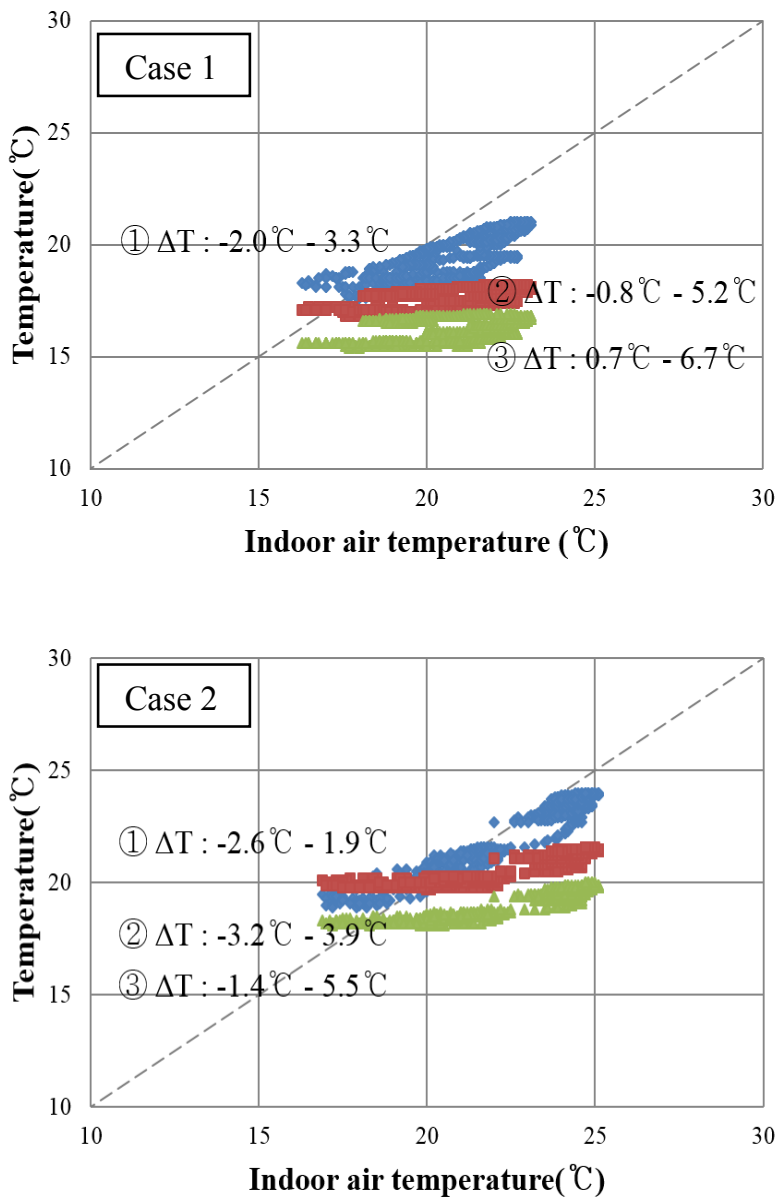

Corresponding author: limit0@ewha.ac.kr 

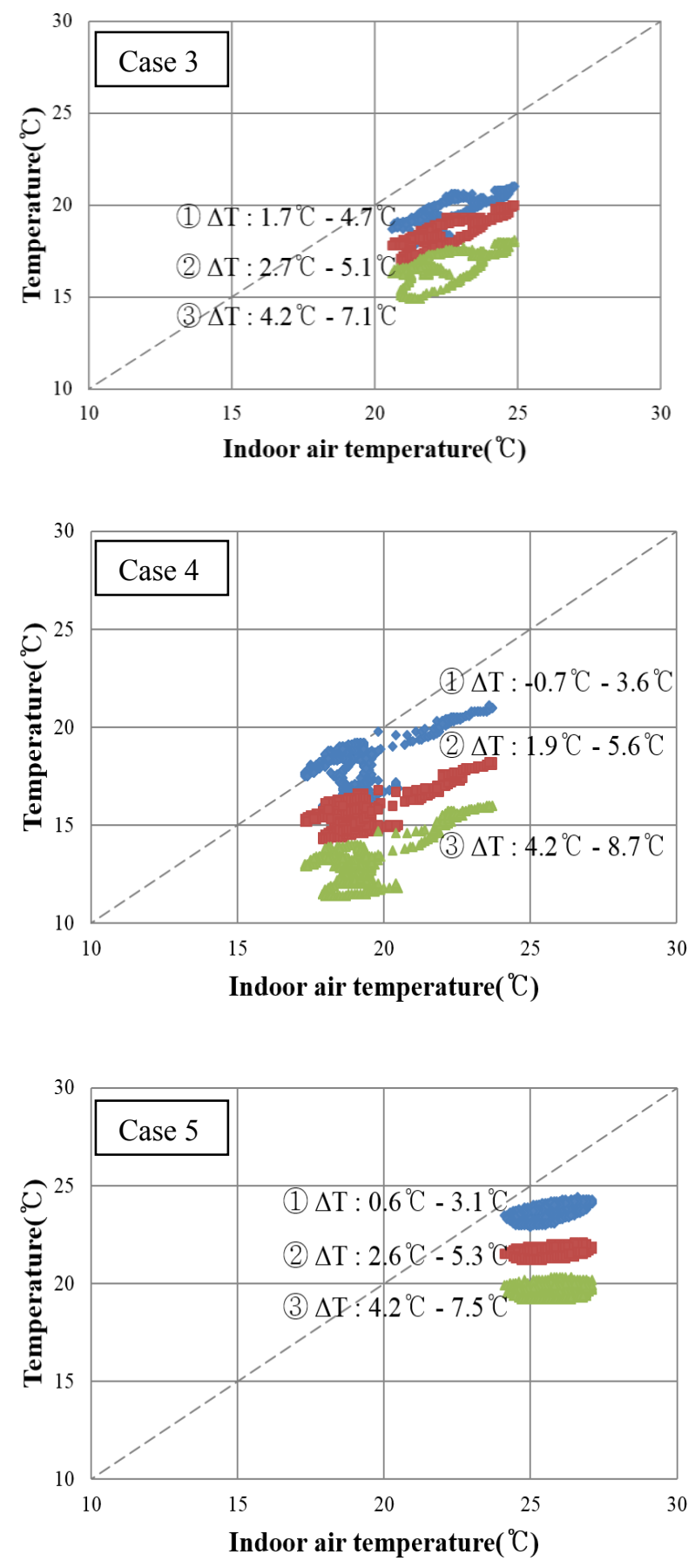

(1) Indoor air temperature - Inside built-in wardrobe temperature

(2) Indoor air temperature - Upper part temperature of behind built-in wardrobe A (3) Indoor air temperature - bottom part temperature of behind built-in wardrobe

Fig. 6. Temperature ranges and differences between inside the room and inside the built-in wardrobe or in the upper and bottom parts of air cavity at the rear of the wardrobe.

\subsection{Surface temperature changes}

During the measurement, the distribution of surface temperature was identified both on the back panel of built-in wardrobe and on the rear wall. P7 was excluded from the analysis owing to data error. Figure 7 illustrates the ranges of surface temperature on the back panel of built-in wardrobe and on the rear wall.
All the alternatives except Case 2 clearly displayed a vertical temperature stratification. Generally, the surface temperature was lowest at the bottom part of a measurement point, followed by at the middle and upper parts. The lowest surface temperature was measured in the bottom parts of the back panel of the built-in wardrobe and the rear wall. In addition, among the upper and middle measurement points, $\mathrm{P} 4$ and $\mathrm{P} 13$, which were adjacent to the balcony that made contact with the outdoor air, showed low surface temperatures. Consequently, the bottom parts of the back panel of the built-in wardrobe and the rear wall seemed to be vulnerable to condensation.

To determine the temperature difference between the rear wall at the back of the built-in wardrobe and the back panel, the difference in surface temperature among horizontally parallel points was checked. In Case 1 and Case 2, the temperature difference of horizontally parallel points between the rear wall and the back panel ranged from $0{ }^{\circ} \mathrm{C}-1.6{ }^{\circ} \mathrm{C}$. The temperature difference intermittently exceeded $1{ }^{\circ} \mathrm{C}$, but was less than $1{ }^{\circ} \mathrm{C}$ most of the time. However, in Case 3, 4, and 5, which were side houses, the surface temperatures of the rear wall were lower than those of the back panel by $0{ }^{\circ} \mathrm{C}-2.6^{\circ} \mathrm{C}, 0{ }^{\circ} \mathrm{C}$ $-5.1{ }^{\circ} \mathrm{C}$, and $0{ }^{\circ} \mathrm{C}-3.1{ }^{\circ} \mathrm{C}$, respectively. Accordingly, the side houses showed a larger difference in surface temperature between the back panel of the built-in wardrobe and the rear wall than the middle houses.
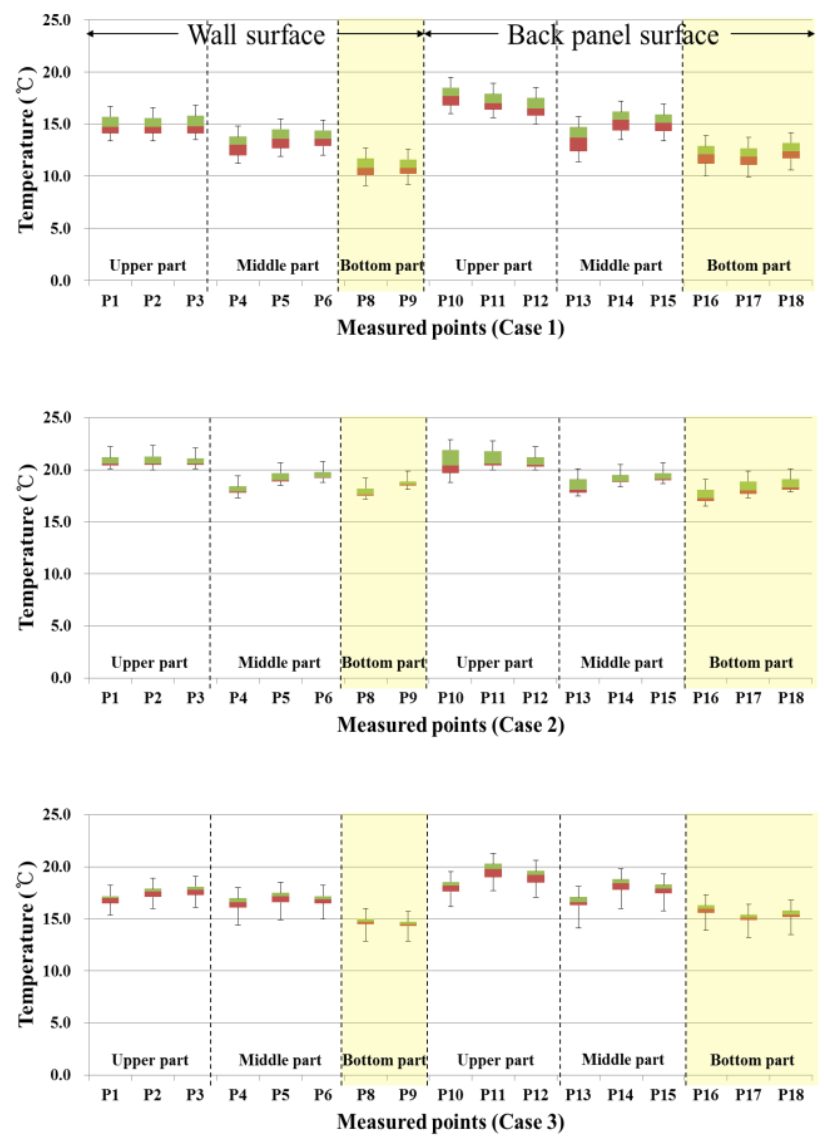

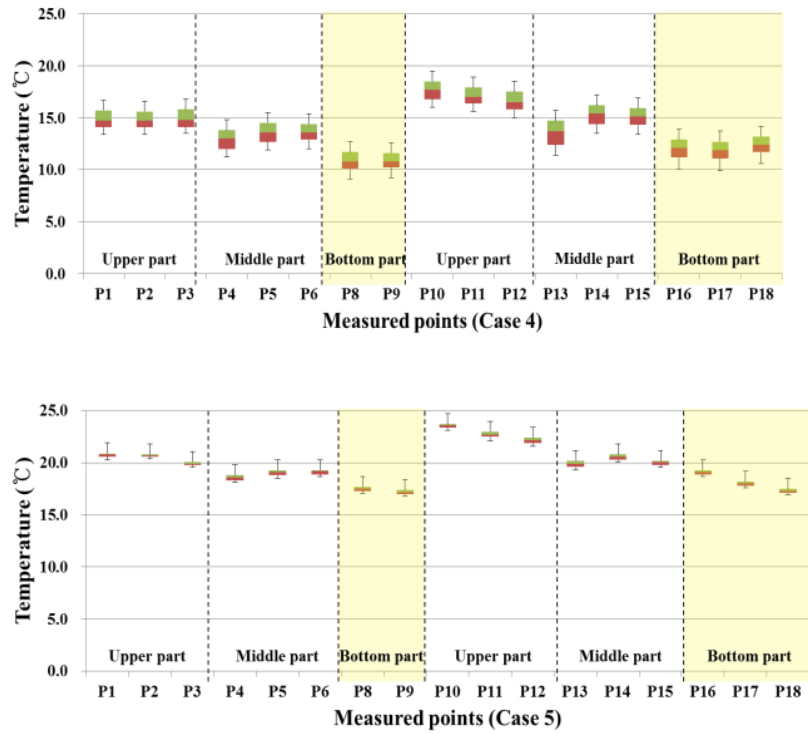

Fig. 7. Distribution of surface temperature at measurement points of each alternative.

\subsection{Condensation occurrence}

In the experiment, the condensation risk time was defined to be the moment where the surface temperature of a measurement point becomes lower than the dew point temperature. The analysis results revealed that all the cases except Case 4, which was a side house, kept the surface temperatures of the back panel of the built-in wardrobe and the rear wall above the dew point temperatures measured inside the wardrobe and in the air cavity at the rear of the wardrobe. In other words, no condensation occurred.

Table 4 presents the condensation risk time and ratio at each measurement point in Case 4. Among the measurement points, the bottom part of the built-in wardrobe, which had the lowest distribution of surface temperature, showed a condensation risk time. The thermal environments of the space of the built-in wardrobe in Case 4 for with and without condensation alternatives were comparatively analysed. The side houses were compared during the experiment. It turned out that, when condensation occurred in Case 4 , the average indoor relative humidity was $69.5 \%$ and the average relative humidity inside the built-in wardrobe was $73.7 \%$. Thus, a highly humid condition was maintained (see Table 5).

\section{Discussion}

\subsection{Effects of auxiliary heating device operation}

In the experiment, every experimental alternative except Case 2 showed vertical stratification of surface temperature. Furthermore, there was a conspicuous temperature drop inside the room, inside the built-in wardrobe, and in both upper and bottom parts of the air cavity at the rear of the wardrobe. In particular, the
Table 4. Condensation risk time and ratio in the vulnerable points of built-in wardrobe (Case 4 ).

\begin{tabular}{|c|c|c|c|c|c|}
\hline & P8 & P9 & P16 & P17 & P18 \\
\hline \multirow{2}{*}{ Case 4} & $5.1 \mathrm{~h}$ & $9 \mathrm{~h}$ & $23.3 \mathrm{~h}$ & $23.6 \mathrm{~h}$ & $23.3 \mathrm{~h}$ \\
& $(5 \%)$ & $(9 \%)$ & $(24 \%)$ & $(24 \%)$ & $(24 \%)$ \\
\hline
\end{tabular}

Table 5. Temperature and humidity ranges with or without condensation risk (Case 4).

\begin{tabular}{|c|c|c|c|c|c|}
\hline & & \multicolumn{2}{|c|}{$\begin{array}{c}\text { Condensation risk } \\
\mathrm{x}\end{array}$} & \multicolumn{2}{c|}{$\begin{array}{c}\text { Condensation risk } \\
\text { O }\end{array}$} \\
\hline \multirow{4}{*}{ Room } & & $\mathrm{T}\left({ }^{\circ} \mathrm{C}\right)$ & $\mathrm{RH}(\%)$ & $\mathrm{T}\left({ }^{\circ} \mathrm{C}\right)$ & $\mathrm{RH}(\%)$ \\
\cline { 2 - 6 } & Min. & 17.3 & 11 & 18.2 & 13 \\
\cline { 2 - 6 } & Max. & 23.6 & 88 & 23.7 & 90 \\
\cline { 2 - 6 } & Ave. & 18.8 & 42.8 & 21.8 & 69.5 \\
\hline \multirow{3}{*}{$\begin{array}{c}\text { Built-in } \\
\text { wardrobe }\end{array}$} & Min. & 15.9 & 15 & 16.2 & 24 \\
\cline { 2 - 6 } & Max. & 21.1 & 75 & 21 & 81 \\
\cline { 2 - 6 } & Ave. & 17.5 & 36.7 & 19.9 & 71.8 \\
\hline
\end{tabular}

bottom surface temperature and the temperature in the bottom air cavity dropped by as much as $5.4{ }^{\circ} \mathrm{C}$ and $7.5^{\circ} \mathrm{C}$, respectively. This seems to be because the floor-heating coil was not installed beneath the built-in wardrobe, and no heat insulation was installed in the shaft, which resulted in local heat loss.

In each house where measurement was conducted, the condensation vulnerable areas of the built-in wardrobes turned out to be the bottom parts of the wardrobes (P8, P9, P16, P17, and P18). However, the experiment also checked whether the auxiliary heating device installed in the upper part could expand the increase in surface temperature to the bottom part. As illustrated in Figure 8, the effect of the auxiliary heating device on the surface temperature change in the bottom condensation vulnerable areas was identified through cumulative distribution of surface temperature in those areas in Case 3 and Case 5, for which the experiment was performed under the same outdoor temperature and humidity conditions. The experimental result revealed that the surface temperature in condensation vulnerable areas for Case 5 with the auxiliary heating device experienced a larger increase of $1{ }^{\circ} \mathrm{C}-4.9^{\circ} \mathrm{C}$ than that for Case 3 without such a heating device. Accordingly, even when the auxiliary hating device was installed in the upper part, the heat was transferred down to the bottom parts of the rear wall surface and the wardrobe back panel, which were vulnerable to condensation.

\subsection{Effects of outdoor weather conditions}

To accurately analyse the effect of outdoor weather conditions on the surface temperatures in the middle and side houses, the temperature difference ratio TDR value was used. As an evaluation index for preventing condensation, the TDR value is the relative ratio of 


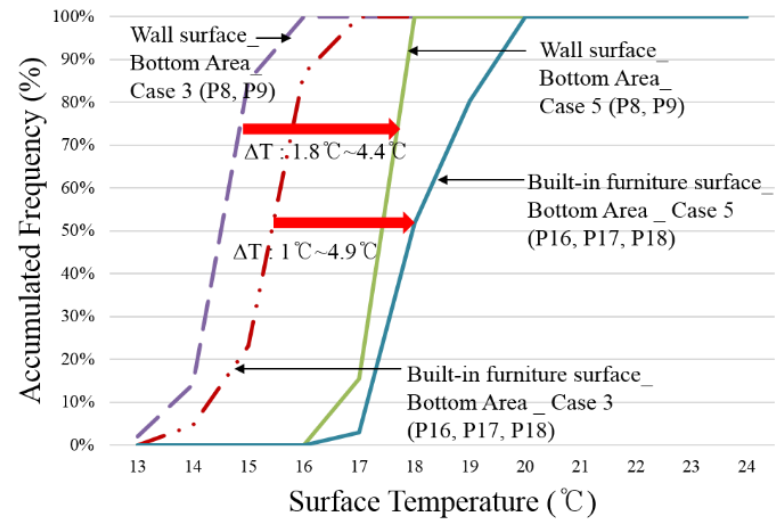

Fig. 8. Cumulative distribution of surface temperature in the upper and bottom parts of the rear wall and back panel of the built-in wardrobe (Case 3, Case 5).

indoor and outdoor to indoor and indoor surface temperatures. The equation for calculating the TDR value is as follows.

$$
\mathrm{TDR}=\frac{T_{i}-T_{\text {sur }}}{T_{i}-T_{o}}
$$

$\mathrm{T}_{\mathrm{i}}=$ Indoor temperature

$\mathrm{T}_{\mathrm{o}}=$ Outdoor temperature

$\mathrm{T}_{\text {sur }}=$ Surface temperature

The condensation vulnerable areas of Case 2 and Case 5, for which the experiment was conducted under the same outdoor and indoor temperature and humidity conditions, were converted to TDR values, as presented in Figure 9 and Figure 10. Unlike Case 5, Case 2 had a uniform distribution of surface temperature on the rear wall and the back panel of the built-in wardrobe when the auxiliary heating device was operated. As for the condensation vulnerable areas on the rear wall of the built-in wardrobe, Case 2 showed a 0.46-0.98 lower TDR value than Case 5. Moreover, in the condensation vulnerable areas of the back panel of the built-in wardrobe, Case 2 had a 0-0.5 lower TDR value than Case 5. It seems to be because the middle house, which is less affected by outdoor air than the side house, could keep a higher surface temperature. In this regard, the wall surface temperature at the rear of the built-in wardrobe could be maintained on par with that of the wardrobe back panel.

To analyse the change in surface temperature according to the outdoor temperature drop, TDR values were also calculated for condensation vulnerable areas of Case 4 and Case 5, which were subjected to different outdoor weather conditions during the experiment. Figure 11 and Figure 12 provides the TDR values. Case 4, which was subject to lower outdoor temperatures, had a higher TDR value than Case 5. In the condensation vulnerable areas on the rear wall of the built-in wardrobe, Case 4 showed a 0-0.42 higher TDR value than Case 5. Furthermore, in the condensation vulnerable areas of the back panel of the built-in wardrobe, Case 4 had a 0-0.35 higher TDR value than Case 5. Consequently, during severe cold in winter, condensation risk will not be completely eliminated by increasing the surface temperature of condensation vulnerable areas in built-in wardrobe above the dew point temperature. Thus, if the auxiliary heating device is installed in the bottom part of the built-in wardrobe back panel or another heating device is used, condensation will be prevented more effectively.

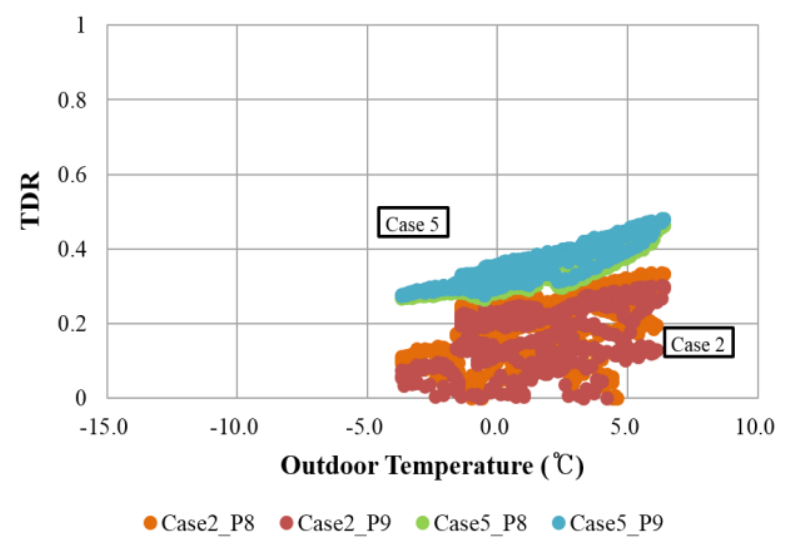

Fig. 9. TDR value of condensation vulnerable areas ait the bottom part of the wall at the rear of the built-in wardrobe (Case 2, Case 5).

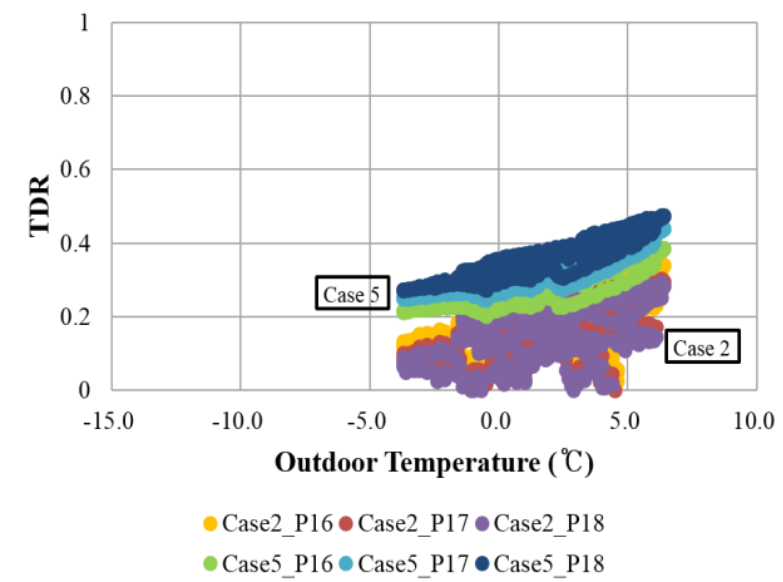

Fig. 10. TDR value of condensation vulnerable areas in the bottom part of the built-in wardrobe back panel(Case 2, Case 5).

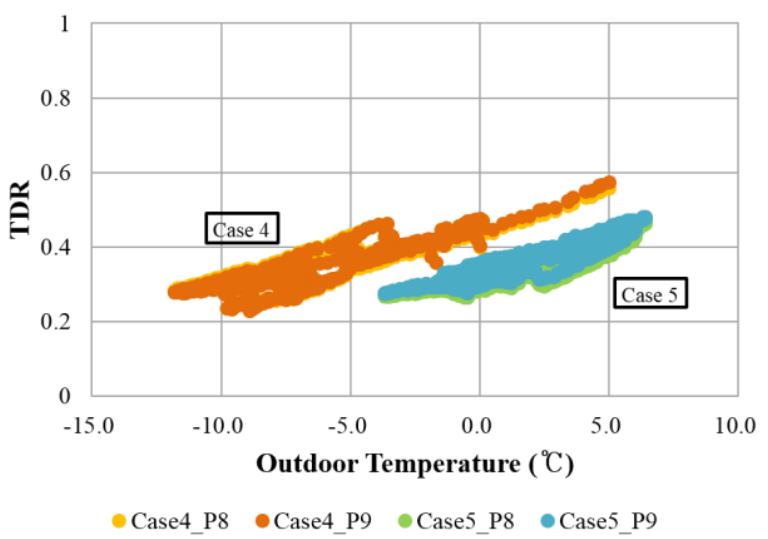

Fig. 11. TDR value of condensation vulnerable areas in the bottom part of the wall at the rear of built-in wardrobe (Case 4, Case 5). 


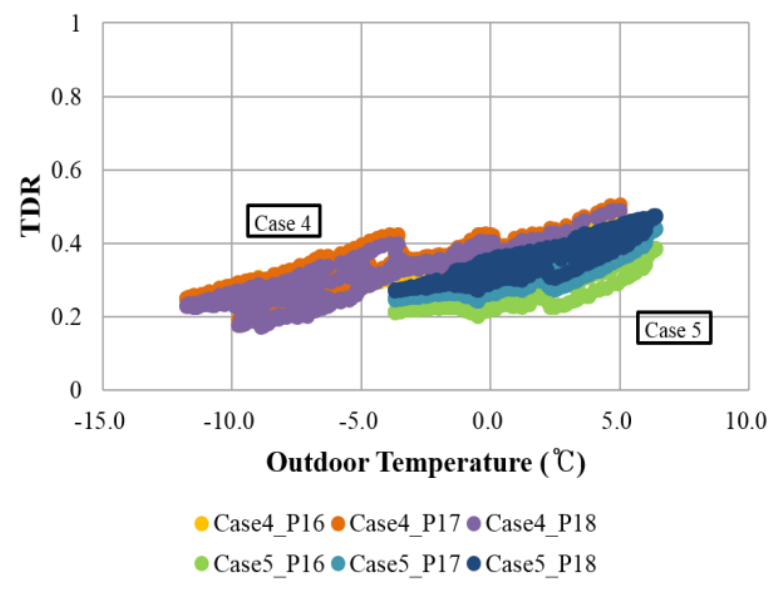

Fig. 12. TDR value of condensation vulnerable areas in the bottom part of the built-in wardrobe back panel (Case 4, Case $5)$.

\section{Conclusion}

This study analyse the thermal environment of a built-in wardrobe installed close to outdoor air in an existing apartment building. The temperature and humidity were measured inside the built-in wardrobe and in the air cavity between the wardrobe and the rear wall according to the operation of an auxiliary heating device. The internal environment of a real built-in wardrobe was reproduced to see the effect of the auxiliary heating device on condensation reduction in vulnerable areas inside the wardrobe. In the field experiment during winter, the side houses with the auxiliary heating device showed condensation at a high humidity under severe cold weather conditions. When the auxiliary heating device installed in a vent, which was located in the upper part of the built-in wardrobe, was operated, the overall surface temperature of the built-in wardrobe increased. However, in cases where the relative humidity was high or the outdoor temperature in winter was very low while the floor heating system was being operated, condensation could not be completely prevented. Accordingly, the surface temperature of condensation vulnerable areas in the bottom part of the built-in wardrobe could be maintained above the dew point temperature by increasing the number of auxiliary heating devices or changing the location of the heating device to the bottom part of the wardrobe. In a future study on the condensation problem of built-in wardrobes, the effect of a vent on reducing humidity in the space where the built-in wardrobe is installed will be evaluated.

This research was supported by a grant (19RERPB082204-06) from the Residential Environment Research Program funded by the Ministry of Land, Infrastructure and Transport of Korean government.

\section{References}

1. Oh, H.R., Lee, H.H., Lim, J.H., Song, S.Y., Eval. O. A. 33, 6, 87-94 (2017)
2. Oh, S.M., Park, S.H., Kwang, S.J., Stud. O. K. 29, 2, 82-88 (2016)

3. Lee, H.H., Oh, H.R., Lim, J.H., Song, S.Y., Eval. O A. 32, 7, 131-140 (2016)

4. Korea Infrastructure Safety Corporation, Case. O. (2016)

5. Ministry of Land, Infrastructure and Transport, Buil. E (2017)

6. Lee, H.H., Lim, J.H., Song, S.Y., Asse. O. A. 33, 12, 99-106 (2017)

7. Chun, C.Y., Kim, H.J., Bae, N.R., Rese. O. A. 21, 8, 209-216 (2005)

8. Kim, G.T., Kim, J.Y., Hwang, H.J., Kim, K.S.,The D. L. 5, 4, 291-296 (2014)

9. Hwang, H.J., Kim, G.T., Yoo, J.H., Hwang, I.T., An I. K. 9, 4, 319-324 (2015)

10. Lee, H.H., A Stu., D (2017) 